\title{
Screening the Cucumber Plant Introduction Collection for Young Fruit Resistance to Phytophthora capsici
}

\author{
Marivi Colle, Elizabeth N. Straley, Stephanie B. Makela, \\ Sue A. Hammar, and Rebecca Grumet ${ }^{1}$ \\ Department of Horticulture and Graduate Program in Plant Breeding, \\ Genetics, and Biotechnology, 1066 Bogue Street, Michigan State University, \\ East Lansing MI 48824
}

Additional index words. cucumber, Cucumis sativus, disease resistance, Phytophthora capsici, Phytophthora fruit rot

\begin{abstract}
Fruit rot caused by Phytophthora capsici is a major constraint in cucumber (Cucumis sativus) production. In an effort to identify a source of resistance, we developed a more streamlined detached fruit method for high-throughput screening and tested the U.S. cucumber PI collection for fruit rot resistance. A total of 1076 PI collections, from 54 geographic locations around the world, along with the susceptible commercial cultivar, Vlaspik, were grown in the field and tested for resistance to $P$. capsici. Using the knowledge gained from our prior studies regarding greater susceptibility of young fruits compared with older fruits, very young fruits $(\approx 3$ to 4 days post-pollination) were collected and inoculated with zoospore suspensions of $P$. capsici isolate OP97. From the screens performed in 2011 and 2012, 99\% of the tested PIs were rated as moderately or highly susceptible based on symptom development and pathogen growth at 5 days postinoculation. The cv. Vlaspik control showed consistent high susceptibility to $P$. capsici with a mean symptom rating of 8.0 on a 9-point scale. A set of 28 PIs was chosen for further testing in the greenhouse or field in 2013. The disease ratings of PIs rescreened in 2013 were much lower compared with that of the full collection of PIs. Three accessions, PI109483, PI178884, and PI214049, showed consistent low mean disease ratings and may be considered as possible sources of resistance to young cucumber fruit infection by $P$. capsici. Evaluation of the $S_{1}$ progeny of PI109483 suggests that the resistance is heritable and should allow for development of useful breeding materials that can be used for developing $P$. capsici-resistant cucumber cultivars.
\end{abstract}

Cucumber (Cucumis sativus) production in the eastern and midwestern United States is subject to severe losses resulting from fruit rot caused by the soilborne oomycete pathogen, Phytophthora capsici (Granke et al., 2012; Sonogo and $\mathrm{Ji}, 2012$ ). The disease causes commercial loads of harvested cucumbers to be rejected for sale and farmland to be removed from cucumber production. $P$. capsici has tremendous reproductive potential, allowing for rapid spread both within and

Received for publication 25 Oct. 2013. Accepted for publication 18 Dec. 2013.

This work was in part supported by the Agriculture Research Fund, Pickle Packers International, MSU-GREEEN, and the USDA National Institute of Food and Agriculture Special Research Grant No. 2008-34572-19339 (Phytophthora Research, MI). We thank the North Central Regional Plant Introduction Station, Ames, IA, for providing seeds and Dr. Mary Hausbeck for providing $P$. capsici isolate OP97. We thank Dave Freeville, Andrew Mittin, and Anne Boone for their help in the greenhouse and Bill Chase, Gary Winchell, and their staff for assisting us in the field. We also thank Drs. Jim Kelly and Mitch McGrath for helpful reviews of the manuscript. ${ }^{1}$ To whom reprint requests should be addressed; e-mail grumet@msu.edu. between fields (Granke et al., 2012). The sporangia, which are continuously produced throughout the growing season, release motile infective zoospores on contact with water and provide a constant source of inoculum for new infections. The pathogen also produces sexual oospores, which serve as long-lived overwintering structures. $P$. capsici is notable for its wide host range including numerous solanaceous, cucurbit, and legume crops (Hausbeck and Lamour, 2004; Tian and Babadoost, 2004). The combined effects of broad host range, spread of the disease through infested irrigation water, and the ability of $P$. capsici oospores to survive in the soil for many years makes control by cultural practices very difficult (Gevens et al., 2007; Granke et al., 2012; Sonogo and Ji, 2012). Furthermore, several strains of $P$. capsici isolated from states in the eastern, southern, and midwestern United States have developed resistance to key fungicides, reducing usefulness of some chemical controls (e.g., Café and Ristaino, 2008; Dunn et al., 2010; Jackson et al., 2012; Lamour and Hausbeck, 2000). Collectively these factors dictate that yield losses resulting from $P$. capisci infection will be a continuing problem in cucumber production unless genetic resistance is developed.
Several recent studies have searched for sources of host plant resistance to crown rot and fruit rot caused by $P$. capsici in cucurbit crops. Screening of Cucurbita pepo accessions for crown rot resistance led to identification of eight accessions with low mean disease ratings (Padley et al., 2008). Inheritance studies using a Cucurbita breeding line indicated that resistance is conferred by three dominant genes (Padley et al., 2009). Five accessions of Cucurbita moschata were identified with resistance to Floridian isolates of P. capsici (Chavez et al., 2011); high levels of seedling-stage crown rot resistance were reported in $\mathrm{S}_{1}$ progeny of three melon ( $\mathrm{Cucu}$ mis melo) introductions (Donahoo et al., 2013); and seedling resistance was observed in two accessions of watermelon (Citrullus lanatus var. lanatus) (Kim et al., 2013). Several bottle gourd (Lagenaria siceraria) rootstocks used for grafting with watermelon also were found to confer crown rot resistance (Kousik et al., 2012b). Screening for sources of resistance to Phytophthora fruit rot in watermelon identified four Citrullus lanatus var. lanatus accessions along with a Citrullus lanatus var. citroides and a Citrullus colocynthis accession (Kousik et al., 2012a).

The primary losses caused by $P$. capsici infection of cucumber result from fruit rot (Hausbeck and Lamour, 2004). P. capsici preferentially infects cucumber fruits, whereas leaves and vines remain healthy (Ando and Grumet, 2006; Grumet et al., 2013). Thus, it is essential that screening for resistance is performed directly on fruit. A prior study (Gevens et al., 2006) tested more than 300 cucumber varieties and PIs, including 100 genotypes selected to provide a representative sample of genetic variance in the cucumber germplasm as determined by Knerr et al. (1989). That study did not identify a suitable source of genetic resistance.

In the process of that screening, which was performed on harvest-stage fruit, we observed that larger fruit appeared to be less susceptible than smaller fruit. Analysis of hand-pollinated fruit of known ages ranging from 0 to $16 \mathrm{~d}$ post-pollination (dpp) showed that very young fruit (e.g., 0 to $4 \mathrm{dpp}$ ) were most highly susceptible (Gevens et al., 2006). As fruits completed the period of rapid fruit elongation, at $\approx 10$ to $12 \mathrm{dpp}$, they became less susceptible and were essentially resistant by $16 \mathrm{dpp}$. Developmentally regulated or agerelated resistance wherein resistance increases with plant or tissue age, has been observed in other host plant-pathogen interactions, including $P$. capsici infection of pepper, and subsequent studies with P.capsici infection of other cucurbit fruits (Ando et al., 2009; Develey-Rivière and Galian, 2007; Hwang et al., 1996; Meyer and Hausbeck, 2013). These results have implications for disease control strategies including appropriate location and timing of fungicide applications. They also indicate that it is critical to screen the highly susceptible, young cucumber fruit when testing for resistance to $P$. capsici.

Fruit testing is time-, labor-, and spaceintensive. The objectives of this study were to 
develop a modified testing method to allow for a more efficient inoculation for highthroughput screening using young cucumber fruit and to screen the full U.S. cucumber PI collection for resistance to $P$. capsici. We used knowledge gained in our prior studies regarding greater susceptibility of floral ovaries and very young fruit and lack of difference in susceptibility between pollinated and parthenocarpic fruit (Ando, 2009; Ando et al., 2009; Gevens et al., 2006), to develop a more streamlined fruit screening method and prevent misassessment of potential resistance that can occur as the fruits become older. Screening of the cucumber PI collection identified three accessions as potential sources for young fruit resistance to $P$. capsici.

\section{Materials and Methods}

Seed of 1297 cucumber PI accessions was provided by the North Central Regional Plant Introduction Station, Ames, IA $(<\mathrm{http}: / /$ www.ars-grin.gov/cgi-bin/npgs/html/taxon. pl?12580\#image $>$ ). Of those, 1076 PIs were not previously screened for resistance to $P$. capsici. The 1076 accessions were planted in small-plot, unreplicated trials of three plants/plot at the Michigan State University Horticulture Teaching and Research Center, East Lansing, MI, in the summers of 2011 and 2012. Seeds were planted into $0.8-\mathrm{m}$ wide plastic mulch with $2 \mathrm{~m}$ between rows and $1-\mathrm{m}$ spacing within rows. Local standard commercial production guidelines were followed for fertilization and insect and weed control (Bird et al., 2005). Water was supplied by rain or by trickle irrigation to provide $25 \mathrm{~mm}$ per week. Pollination was facilitated by bees. Once the period of fruit setting began, fruit were harvested two or three times a week until 10 fruit had been collected from each PI. Fruit were collected on 15 dates in 2011 and 20 dates in 2012 . Very young fruits, estimated to be $\approx 3$ to $4 \mathrm{dpp}$ based on fruit size and blossom appearance, were harvested and brought to the laboratory for inoculation.

The harvested fruit were washed, surfacesterilized by brief immersion in a $5 \%$ sodium hypochlorite solution, rinsed with water several times, and allowed to air-dry. A modified inoculation procedure based on the methods of Gevens et al. (2006) was developed to streamline the screening process. Phytophtora zoospore suspensions were prepared from $P$. capsisi isolate OP97 mycelia cultured on diluted V8 agar media as per Gevens et al. (2006). After $7 \mathrm{~d}$ of culture, the plates were flooded with $6 \mathrm{~mL}$ sterile distilled water to release zoospores. A $20-\mu \mathrm{L}$ aliquot was removed for quantitation by a hemocytometer. The remainder was diluted to a concentration of $1 \times 10^{5}$ zoospores $/ \mathrm{mL} ; 30 \mu \mathrm{L}$ of the zoospore suspension was applied to the center of each fruit. Incubation was performed under constant light at 23 to $25^{\circ} \mathrm{C}$ in covered trays lined with wet paper towels to maintain high humidity as described by Gevens et al. (2006). Fruit from the susceptible control 'Vlaspik' were included at each harvest to ensure effectiveness of the inoculation procedure. On rare occasions (less than $1 \%$ of fruit tested), the droplet did not remain on the surface of the fruit. In those cases, an additional one or two droplets were applied; in most cases, the droplet stayed on the surface after the repeat application. In those cases in which the droplet still fell off the surface, the combined droplets created a "pool." The fruits were then placed on top of the pool for
$24 \mathrm{~h}$, a time that our prior methods development tests had shown was sufficient to establish infection. The fruits were then rotated so that the surface that was in contact with the inoculum was visible for scoring. In no case was potential resistance associated with failure of the droplet to remain on the fruit surface. In any case where it was not clear if the droplet ran off the fruit, the fruit was discarded from analysis.

The fruit were monitored daily for symptom development and obvious pathogen growth for a period of at least $5 \mathrm{~d}$. All disease ratings used for analysis were taken at $5 \mathrm{~d}$ post-inoculation. In 2011 the fruit responses were scored using a disease rating scale of 1 to 5 defined as: $1=$ no symptoms; $2=$ mild water-soaking; 3 = water-soaking with necrosis; 4 = extensive water-soaking (may also include necrosis and/or obvious mycelium growth); 5 = tissue collapse (with or without obvious mycelium growth). In 2012 the rating system was modified to a 1 to 9 scale (illustrated in Fig. 1) to better capture the range of symptoms observed among the diverse genotypes. Responses with scores of 1 to 3 (i.e., no symptoms or minor symptoms limited to the point of inoculation) were considered resistant; 4 to 6 (i.e., moderate to extensive water-soaking and/or limited necrosis or mycelial growth), moderately susceptible; and 7 to 9 (i.e., moderate to extensive mycelium growth, sporulation, necrosis, and tissue collapse), highly susceptible.

Based on the initial screen of the full PI collection, 28 accessions were selected for further testing for reproducibility of observed potential resistance. The selected PIs had mean disease scores less than 2 in 2011 or less than 4 in 2012. An additional 16 accessions

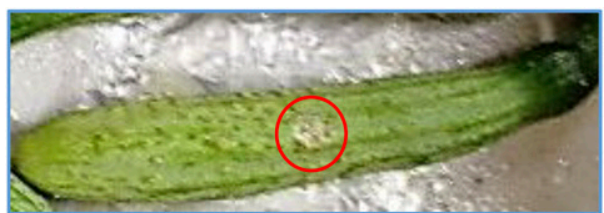

1=no symptom

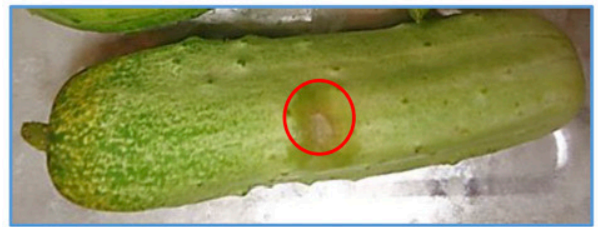

4= moderate necrosis/water soaking

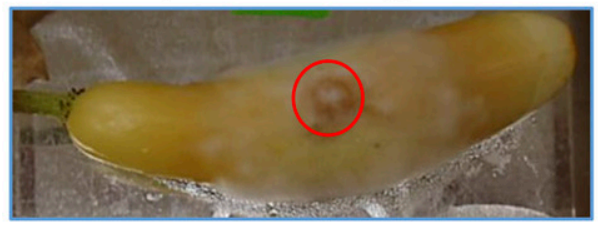

7= extensive symptoms with moderate mycelium growth

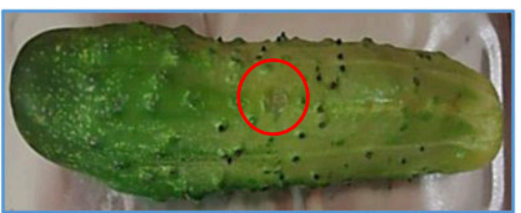

$\mathbf{2}=$ barely visible symptom (necrosis/water soaking)

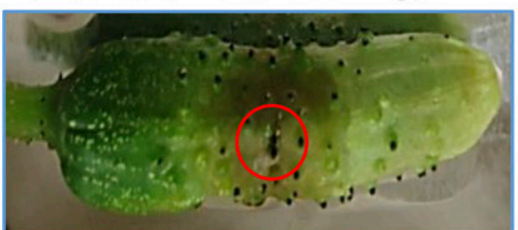

$\mathbf{5}=$ extensive necrosis/water soaking

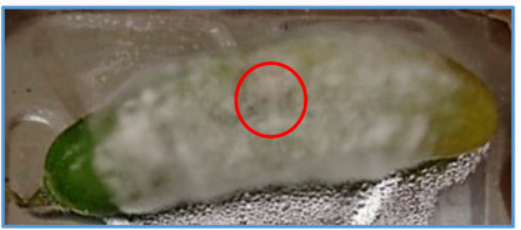

8= extensive mycelium growth

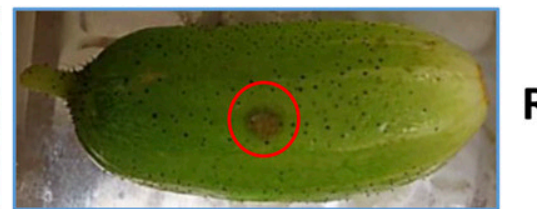

3= visible symptom, limited to site of inoculation

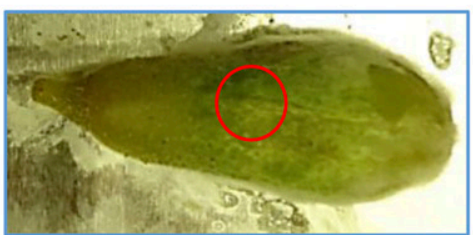

6= extensive necrosis/water soaking with mycelium growth

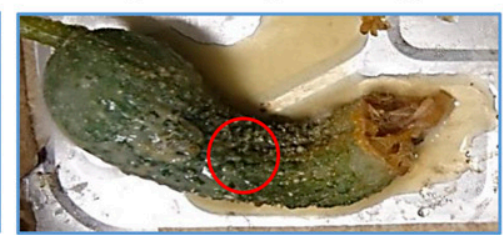

9= tissue collapse

Fig. 1. Symptom rating scale for young cucumber fruit response to inoculation with $P$. capsici. $\mathrm{R}=$ resistant; $\mathrm{S}=$ susceptible; $\mathrm{HS}=$ highly susceptible. 
from the moderate disease rating group that appeared to be segregating for resistance were also included for further testing.

To account for the possibility of segregation within the PI sample, subsequent testing of the putatively resistant PIs in 2013 was performed in the greenhouse and/or field using individual plants. To increase the number of samples that could be tested per plant in the greenhouse, a preliminary study was performed to verify correspondence between the response of unpollinated ovaries from female flowers at anthesis with that of young fruit (data not shown). For the greenhouse trials, five to 10 unpollinated female flowers were collected from each plant at anthesis and ovaries inoculated with zoospore suspensions as described previously. Progeny were produced on three accessions in the greenhouse for which individual plants had been verified to produce resistant fruit: PI109483, PI175693, and Ames 26084. One or two female flowers from those individual plants were hand-pollinated using male flowers from the same plant. Mature fruits were collected at 30 to $35 \mathrm{dpp}$ and seed extracted for field planting in 2013.

Conditions for the 2013 field test were as described previously with the exception that 10 individuals of each potentially resistant PI were planted $2 \mathrm{~m}$ apart within a row, $3 \mathrm{~m}$ between rows, to allow testing of fruit from each plant separately. Harvesting of very young fruits and inoculation with $P$. capsici was performed as described previously. Fruit were harvested on 13 dates. In most cases 10 to 15 fruit were tested per plant with 100 to 200 fruit tested per PI or family sampled over multiple harvest dates.

Data were analyzed by Kruskal-Wallis test in SAS (SAS Institute, Cary, NC) followed by multiple comparisons using the Dunn method.

\section{Results and Discussion}

Sampling of very young fruits from the field, or ovaries from unpollinated flowers at anthesis in the greenhouse, combined with a revised zoospore inoculation procedure allowed us to more quickly prepare and apply inoculum, reduce space needed to perform the inoculation experiments, and prevent misassessment of potential resistance that can occur as the fruits increase in age. The vast majority of the tested PIs were susceptible or highly susceptible to $P$. capsici (Table 1; Fig. 2A-B). By 5 d post-inoculation, nearly $99 \%$ (1064 of 1076) of the accessions had mean symptom ratings 2.0 or greater $/ 5.0$ scale in 2011 or 4.0 or greater/9.0 scale in 2012 indicating effectiveness of the screening method in causing infection. The mean disease rating for the population was $4.5 / 5.0$ in 2011 and 7.3/9.0 in 2012. The control cultivar Vlaspik had ratings of 5.0 and 8.0 in 2011 and 2012, respectively. The very small number of potentially resistant PIs is consistent with the previous screening study in which all of the tested accessions were susceptible to fruit infection by P. capsici (Gevens et al., 2006).

Prior studies by Enzenbacher and Hausbeck (2012) and Gevens et al. (2006) tested several $P$. capsici isolates for virulence on cucurbits. With the exception of one that was less severe than the OP97 isolate used in this study, all were comparable to OP97 for infectivity on cucumber fruit. The virulence of OP97 was further demonstrated by the highly susceptible responses of the great majority of tested accessions (Table 1). These results also indicate effectiveness of the zoospore inoculation procedure, which, in addition to greater ease of application for very large numbers of samples, more closely resembles the primary mode of inoculation in the field.

Of the PIs with very low symptom ratings at $5 \mathrm{~d}$ post-inoculation, there appeared to be two types of responses. Some exhibited delayed and much reduced symptom development (i.e., only some water-soaking without sporulation). Others did not produce symptoms or only showed small, localized necrosis limited to the site of inoculation (e.g., score of 2 or 3 on a 9-point scale; Fig. 1A),

Table 1. Disease scores of the cucumber PI collection for fruit response to inoculation by $P$. capsici. $^{\text {z }}$

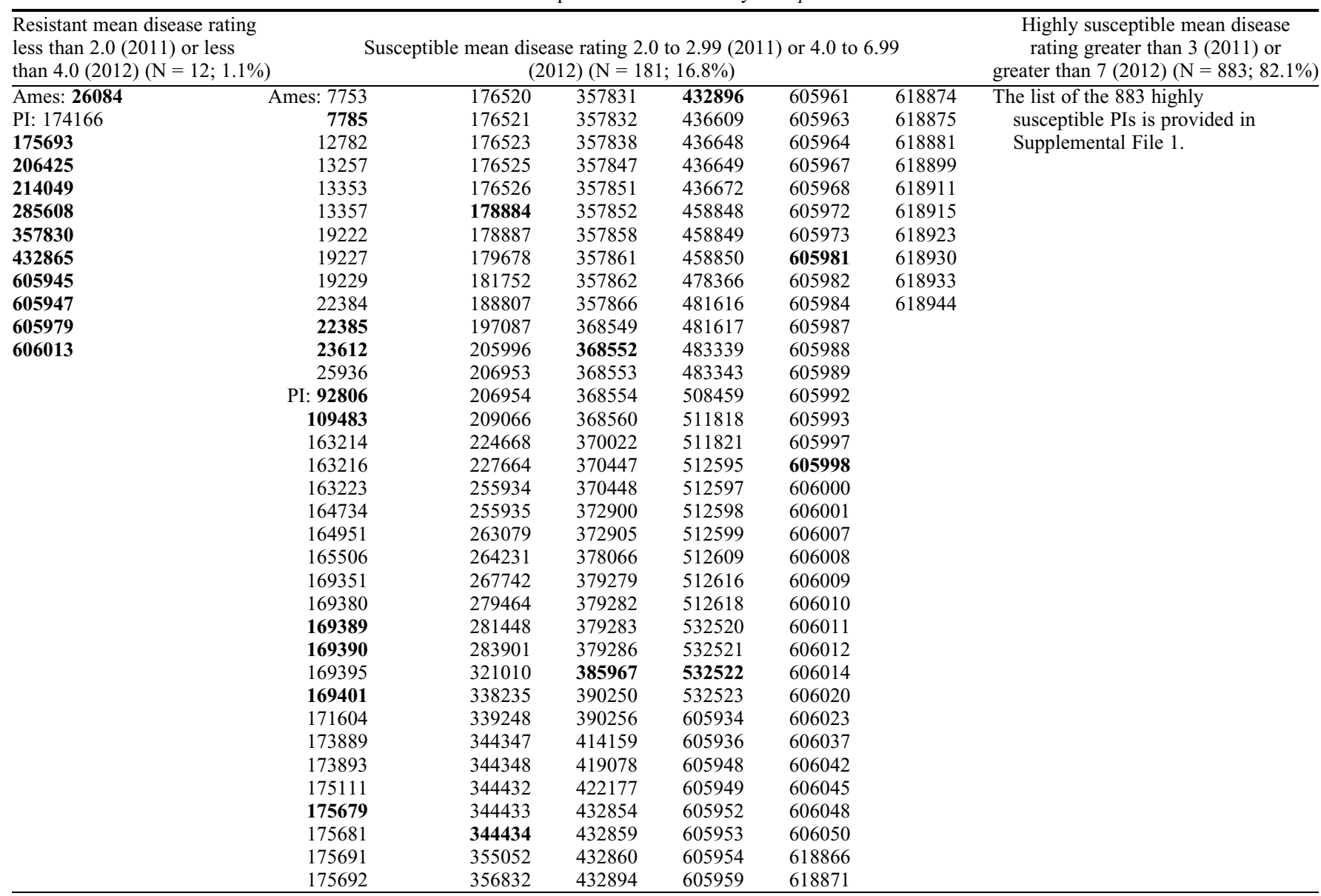

${ }^{\mathrm{z}} \mathrm{A}$ total of 1076 were screened. Disease ratings are the mean of five to 10 young fruit/PI inoculated as described in "Methods." Bold type indicates PIs selected for further testing. 

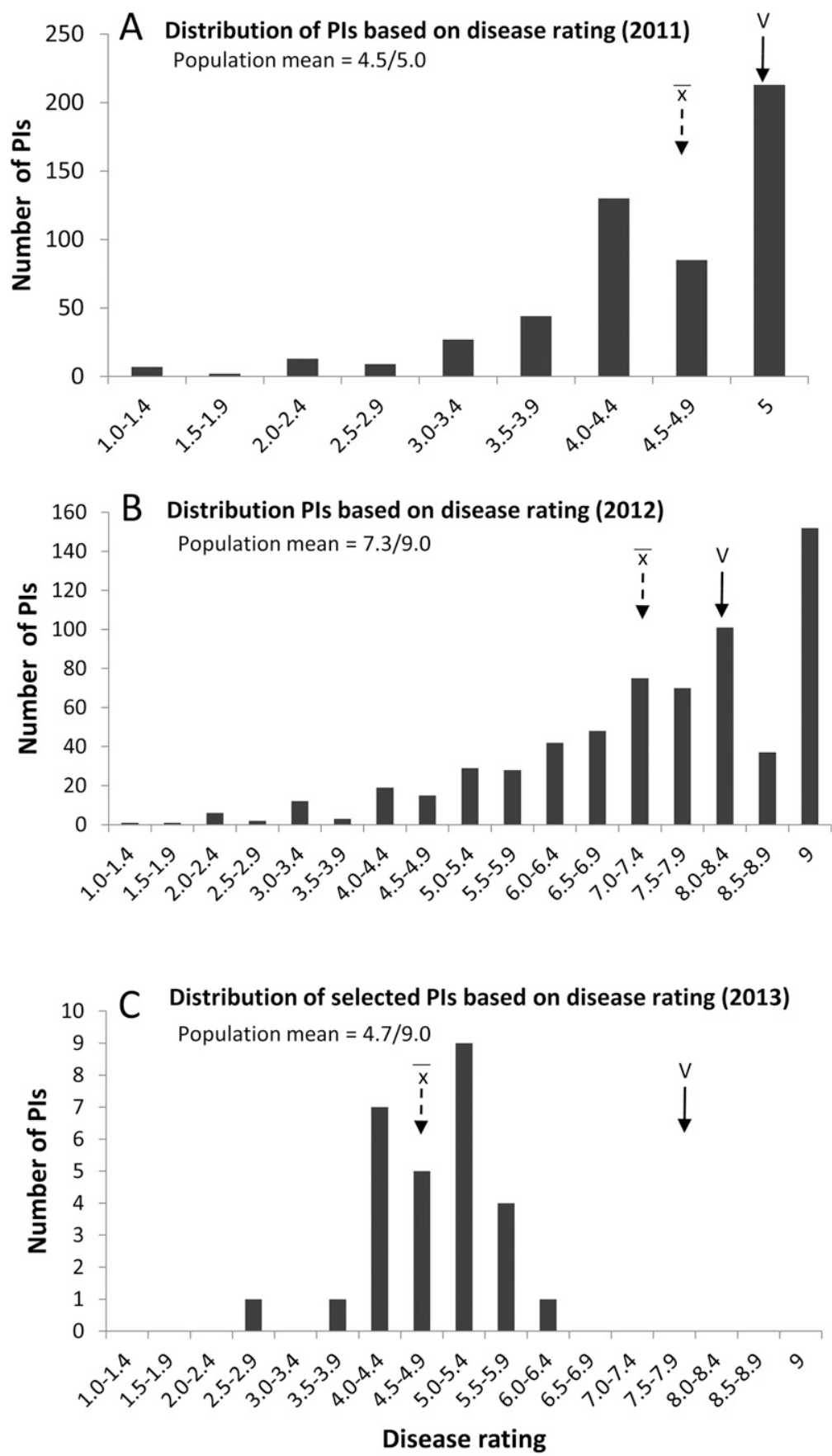

Fig. 2. Distribution of disease scores for cucumber PIs screened for young fruit resistance to P. capsici. (A-B) Distribution of disease scores of PIs from P. capsici inoculation of field-grown fruit in 2011 and 2012. Value for each PI is the mean of five to 0 fruit at $5 \mathrm{~d}$ post-inoculation (dpi). (C) Distribution of disease scores of PIs selected for potential fruit resistance based on screens in 2011 and 2012 and tested as individual plants in 2013. With the exception of three PIs, the value for each PI or S1 family is the mean of 80 to 200 fruit from eight to 10 plants. The disease rating for the susceptible control 'Vlaspik' is indicated by the solid arrows; the mean disease rating for the set of tested PIs is indicated by the dashed arrows.

possibly indicative of a hypersensitive response. In some cases, we observed a mixture of fruit within the same PI sample that exhibited resistant and susceptible responses. Because the close spacing of plants within the initial trials did not allow for differentiation among fruit produced by individual plants, it is possible that a mixed disease response could result from variability within the PI sample. Variability within cucurbit PI accessions for disease resistance responses has been observed frequently (e.g., Davis et al., 2007; Donahoo et al., 2013; Wechter et al., 2011), possibly as a result of a mixed initial sample, or cross-pollination before or after initial collection.

Based on the screens in 2011 and 2012, 28 PIs were chosen for further testing in the greenhouse or field in 2013. In addition to PIs showing resistant phenotypes (mean disease scores less than 2 in 2011 or less than 4 in 2012), 16 accessions from the moderate disease rating group that appeared to be segregating for resistance were included for further testing (Table 1). The majority $(61 \%)$ of the selected PIs were collected from Turkey or India (Table 2). Although there were a greater number of accessions from China in the PI collection, only one showed potential resistance in the 2011-12 screens. This distinction among different geographical regions is consistent with population structure analysis indicating that cucumber germplasm comes from three distinct populations: China; India and Xishuangbanna; and Europe, America, and Central and West Asia (Lv et al., 2012). It appears likely that the resistance arose in Indian and/or West Asian germplasm.

To account for possible variability within the seed sample, subsequent testing of the putatively resistant PIs in 2013 was performed on individual plants. A small number was tested in the greenhouse in the spring of 2013; the majority were tested in the field. $\mathrm{S}_{1}$ progeny were produced on three PIs in the greenhouse. In most cases 10 to 15 fruit were tested per plant with a total of 100 to 200 fruit tested for each PI or $\mathrm{S}_{1}$ family. The PIs retested in the field in 2013 had much lower disease ratings than the full collection of PIs ( $t$ test, $P<0.00001$ ), as evidenced by a shift in the population distribution and a mean disease rating of 4.7 , indicating general reproducibility of resistance for the selected PIs (Fig. 2C; Table 2). The susceptible control, 'Vlaspik', had a rating of 7.7, consistent with results in 2012. In some cases there was a range in mean disease scores for fruit from individual plants within a given accession or family, e.g., PI605979, for which single plant means ranged from 2.1 to 6.5 , suggesting genetic variability or segregation for resistance within the accession (Table 2).

Three accessions (PI 109483 and PI 178884 collected from Turkey and PI 214049 from India) had low PI or family means; multiple plants with mean fruit scores less than 3.5; and $70 \%$ to $90 \%$ of total fruit with disease scores less than 4 (Table 2). In the case of PI 109483, scores from individual fruit in 2012 suggested segregation within the PI seed sample (Table 1). Self-pollinated progeny from greenhouse-grown individual plants with resistant fruit provided several $\mathrm{S}_{1}$ families that showed resistance. Disease progression lines for PIs 109483, 178884, and 214049 showed slow development of necrosis limited to the region of inoculation (Fig. 3). Observation of the fruit for an additional 2 to $3 \mathrm{~d}$ did not show further disease development. Although promising for resistance, PI 214049 was slow to produce female flowers and fruit in Michigan growth conditions (Table 2).

Based on these studies, PI109483, PI178884, and PI214049 may be considered as possible sources of resistance to young cucumber fruit infection by $P$. capsici. Evaluation of the $\mathrm{S}_{1}$ progeny of PI109483 indicates that the resistance is heritable and should allow for development of useful breeding materials that can be used for developing $P$. capsiciresistant cucumber cultivars. As a result of the possible variation or segregation within 


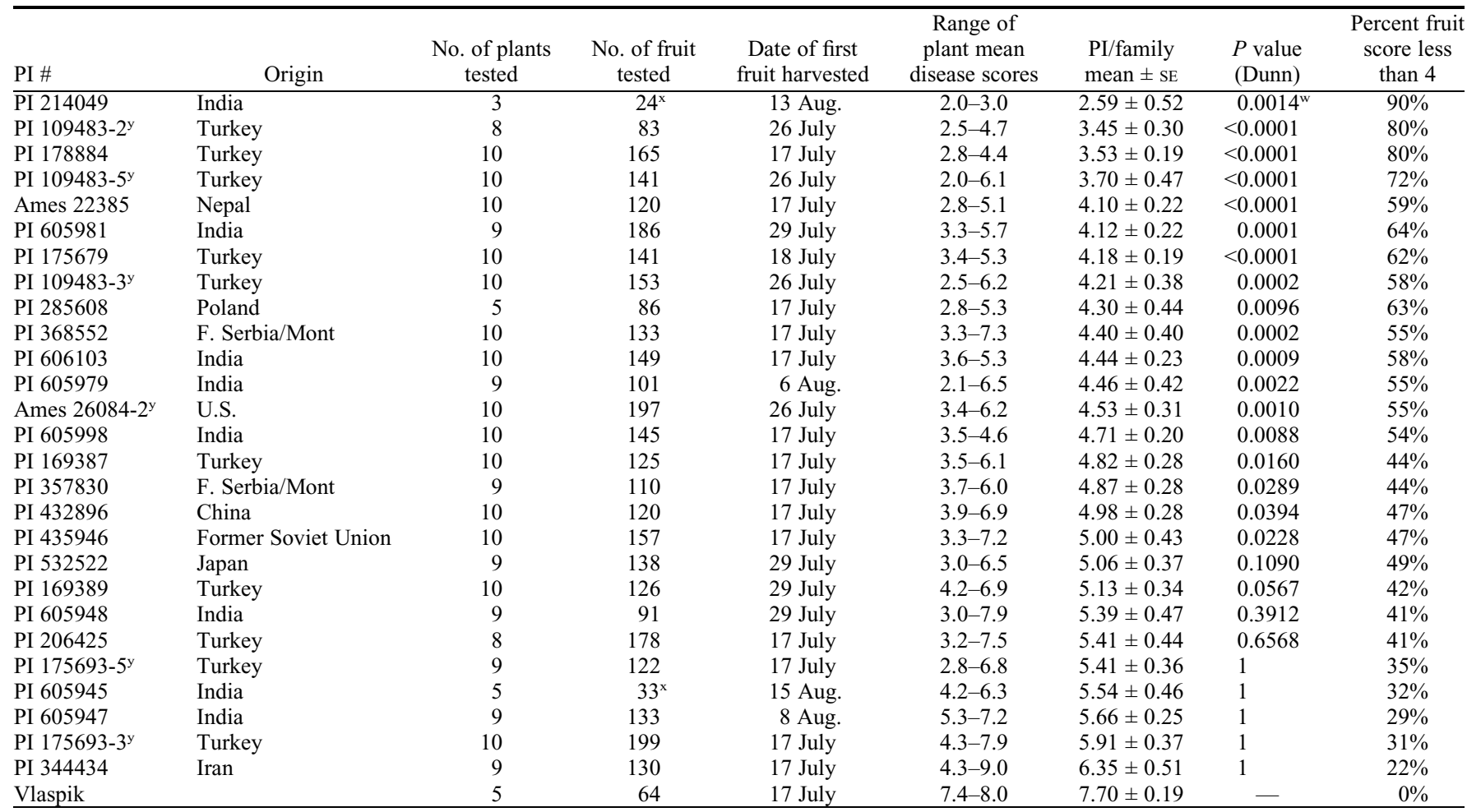

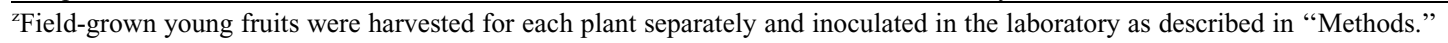

${ }^{\mathrm{y}}$ Denotes $\mathrm{S}_{1}$ progeny family.

${ }^{\mathrm{x}} \mathrm{A}$ limited number of fruit was tested as a result of late production of female flowers and fruit.

"Data were analyzed by Kruskal-Wallis test; $P<0.0001$. $P$ values listed in the table are for Dunn's comparison with control 'Vlaspik'.

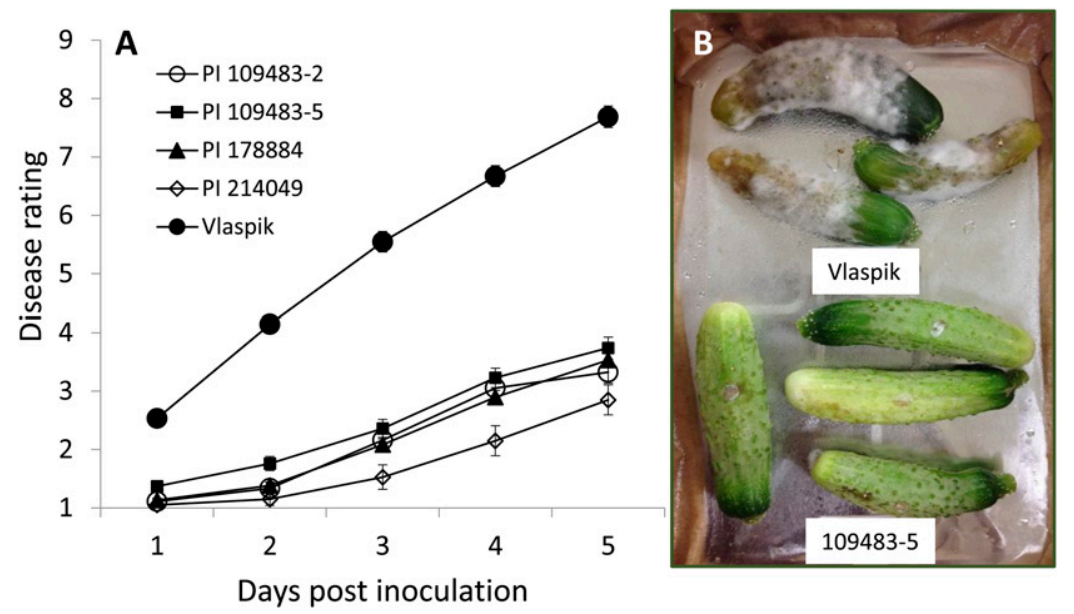

Fig. 3. Response of young fruit of PIs or $\mathrm{S}_{1}$ progeny of 109483, 178884, and 214049 to inoculation by Phytophthora capsici. (A) Disease development curves after inoculation. Disease rating scale is as described in Figure 1; numbers of plants and fruits sampled are indicated in Table 2. (B) Example of disease response of 'Vlaspik' (top) and PI109483-5 $\mathrm{S}_{1}$ (158-5, Plant \#9). The photograph was taken $5 \mathrm{~d}$ post-inoculation. The disease responses of PI 109483 fruit are limited to the site of inoculation (i.e., disease scores of 2 and 3 ).

accessions, it will be important to develop true breeding-resistant stock lines to facilitate future breeding efforts.

\section{Literature Cited}

Ando, K. 2009. Evaluation of the role of plant architecture and cucumber fruit development in Phytophthora capsici disease development. $\mathrm{PhD}$ diss., Michigan State Univ., East Lansing, MI.
Ando, K. and R. Grumet. 2006. Evaluation of altered plant architecture as a means to reduce Phytophthora capsici disease incidence on cucumber fruit. J. Amer. Soc. Hort. Sci. 131: 491-498.

Ando, K., S. Hammar, and R. Grumet. 2009. Agerelated resistance of diverse cucurbit fruit to infection by Phytophthora capsici. J. Amer. Soc. Hort. Sci. 134:176-182.

Bird, G., B. Bishop, E. Grafius, M. Hausbeck, L. Jess, W. Kirk, and W. Pett. 2005. Insect disease and nematode control for commercial vegetables. Michigan State University Ext. Bull. E312, Cucumber section. p. 55-61.

Café, A.C. and J.B. Ristaino. 2008. Fitness of isolates of Phythophthora capsici resistant to mefenoxam from squash and pepper fields in North Carolina. Plant Dis. 92:1439-1443.

Chavez, D.J., E.A. Kabelka, and J.X. Chaparro. 2011. Screening of Cucurbita moschata Duchesne germplasm for crown rot resistance to Floridian isolates of Phytophthora capsici Leonian. HortScience 46:536-540.

Davis, A.R., A. Levi, L. Tetteh, and T.C. Wehner. 2007. Evaluation of watermelon and related species for resistance to race $1 \mathrm{~W}$ powdery mildew. J. Amer. Soc. Hort. Sci. 132:790-795.

Develey-Rivière, M.P. and E. Galian. 2007. Resistance to pathogens and host developmental stage: A multifaceted relationship within the plant kingdom. New Phytol. 175:405-416.

Donahoo, R.S., W.W. Turechek, J.A. Thies, and C.S. Kousik. 2013. Potential sources of resistance in U.S. Cucumis melo PIs to crown rot caused by Phytophthora capsici. HortScience 48:164-170.

Dunn, A.R., M.G. Milgroom, J.C. Meitz, A. McLeod, W.E. Fry, M.T. McGrath, H.R. Dillard, and C.D. Smart. 2010. Population structure and resistance to mefenoxam of Phytophthora capsici in New York State. Plant Dis. 94:14611468.

Enzenbacher, T.B. and M.K. Hausbeck. 2012. An evaluation of cucurbits for susceptibility to cucurbitaceous and solanaceous Phytophthora capsici isolates. Plant Dis. 96:1404-1414.

Gevens, A.J., K. Ando, K.H. Lamour, R. Grumet, and M.K. Hausbeck. 2006. A detached cucumber fruit method to screen for resistance to Phytophthora capsici and effect of fruit age on susceptibility to infection. Plant Dis. 90:1276-1282. 
Gevens, A.J., R.S. Donahoo, K.H. Lamour, and M.K. Hausbeck. 2007. Characterization of Phytophthora capsici from Michigan surface irrigation water. Phytopathology 97:421-428.

Granke, L.L., L. Quesada-Ocampo, K. Lamour, and M.K. Hausbeck. 2012. Advances in research on Phytophthora capsici on vegetable crops in the United States. Plant Dis. 95:15881600 .

Grumet, R., M. Colle, K. Ando, D.S. Xie, L. Havenga, and J.A. Switzenberg. 2013. Modified plant architecture to enhance crop disease control: Genetic control and possible value of upright fruit position in cucumber. Eur. J. Plant Pathol. 135:545-560.

Hausbeck, M. and K. Lamour. 2004. Phytophthora capsici on vegetable crops: Research progress and management challenges. Plant Dis. 88: 1292-1302.

Hwang, B.K., Y.J. Kim, and C.H. Kim. 1996. Differential interactions of Phytophthora capsici isolates with pepper genotypes at various plant growth stages. Eur. J. Plant Pathol. 102:311-316.

Jackson, K.L., Y.F. Yin, and P.S. Ji. 2012. Sensitivity of Phytophthora capsici on vegetable crops in Georgia to mandipropamid, dimethomorph, and cyazofamid. Plant Dis. 96:1337-1342.
Kim, M.J., C.K. Shim, Y.K. Kim, H.J. Jee, S.J. Hong, J.H. Park, and E.J. Han. 2013. Evaluation of watermelon germplasm for resistance to Phytophthora blight caused by Phytophthora capsici. Plant Pathol. J. 29 87-92.

Knerr, L.D., J.E. Staub, D.J. Holder, and B.P. May. 1989. Genetic diversity in Cucumis sativus L. assessed by variation at 18 allozyme coding loci. Theor. Appl. Genet. 78:119-128.

Kousik, C.S., R.S. Donahoo, and R. Hassell. 2012a. Resistance in watermelon rootstocks to crown rot caused by Phytophthora capsici. Crop Prot. 39:18-25.

Kousik, C.S., J.L. Ikerd, P. Wechter, H. Harrison, and A. Levi. 2012b. Resistance to Phytophthora fruit rot of watermelon caused by Phytophthora capsici in U.S. plant introductions HortScience 47:1682-1689.

Lamour, K.H. and M.K. Hausbeck. 2000. Mefenoxam insensitivity and the sexual stage of Phythophtora capsici in Michigan cucurbit fields. Phytopathology 90:396-400.

Lv, J., J.J. Qi, Q.X. Shi, D. Shen, S.P. Zhang, G.J. Shao, H. Li, Z.Y. Sun, Y.Q. Weng, Y. Shang, X.F. Gu, X.X. Li, X.G. Zhu, J.Z. Zhang, R. van Treuren, W. van Dooijeweert, Z.H. Zhang, and S.W. Huang. 2012. Genetic diversity and population structure of cucumber (Cucumis sativus L.). PLoS One e46919.

Meyer, M.D. and M.K. Hausbeck. 2013. Age-related resistance to Phytophthora fruit rot in 'Dickenson Field' processing pumpkin and 'Golden Delicious' winter squash fruit. Plant Dis. 97:446-452.

Padley, L.D., E.A. Kabelka, and P.D. Roberts. 2009. Inheritance of resistance to crown rot caused by Phytophthora capsici in Cucurbita. HortScience 44:211-213.

Padley, L.D., E.A. Kabelka, P.D. Roberts, and R. French. 2008. Evaluation of Cucurbita pepo accessions for crown rot resistance to isolates of Phytophthora capsici. HortScience 43: 1996-1999.

Sonogo, S. and P.S. Ji. 2012. Integrated management of Phytophthora capsici on solanaceous and cucurbitaceous crops: Current status, gaps in knowledge and research needs. Can. J. Plant Pathol. 34:479-492.

Tian, D. and M. Babadoost. 2004. Host range of Phytophthora capsici from pumpkin and pathogenicity of isolates. Plant Dis. 88:485-489.

Wechter, W.P., A. Levi, K.S. Ling, C.S. Kousik, and C.C. Block. 2011. Identification of resistance to Acidovorax avenae subsp. citrull among melon (Cucumis spp.) plant introductions. HortScience 46:207-212. 


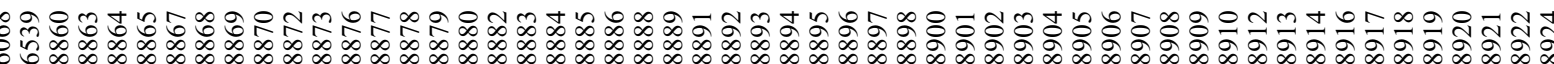

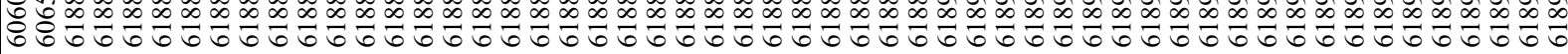

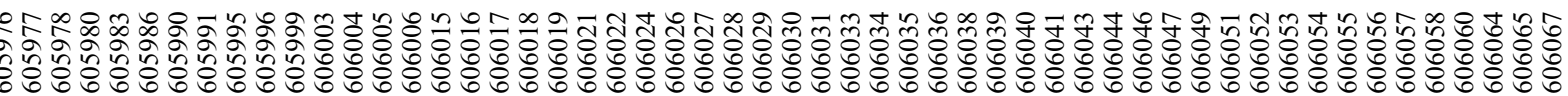

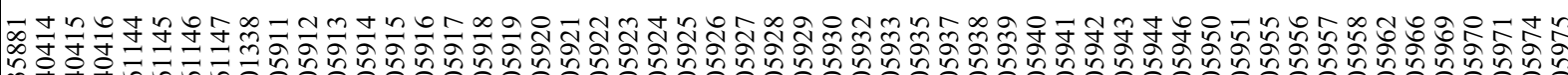

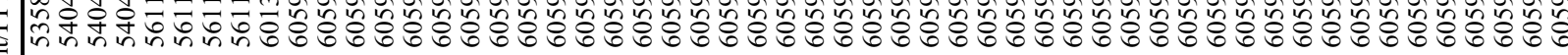

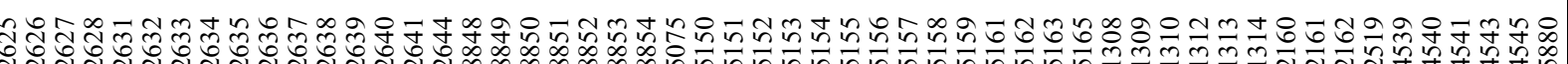

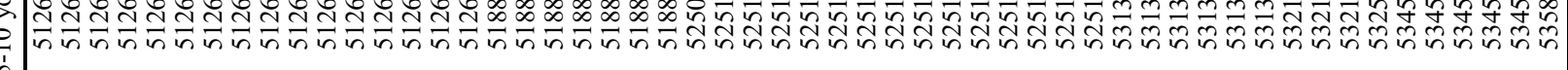

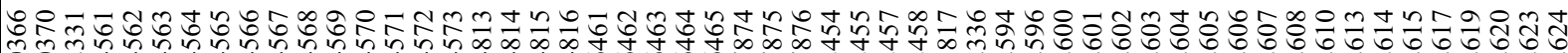

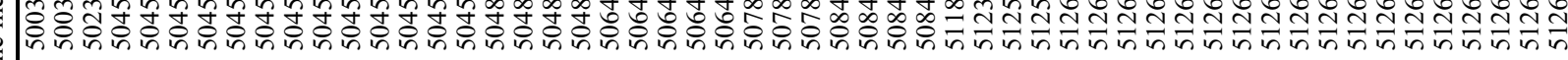

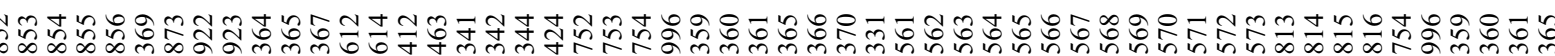
等

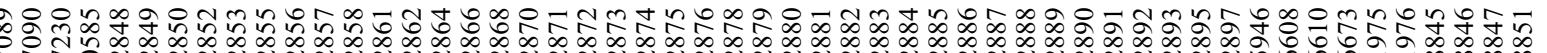

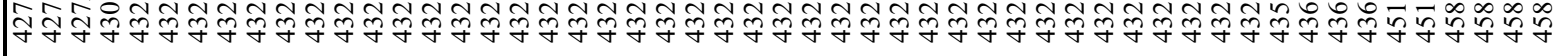

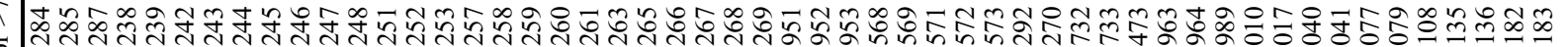

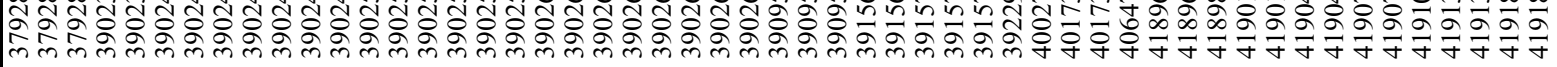

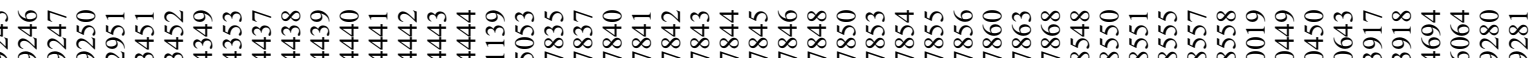

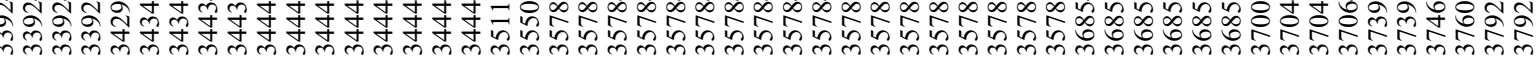

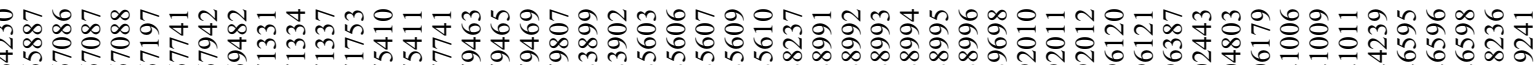

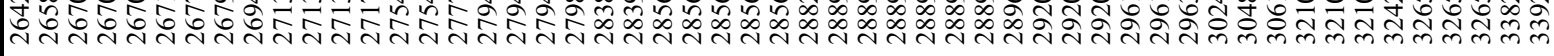

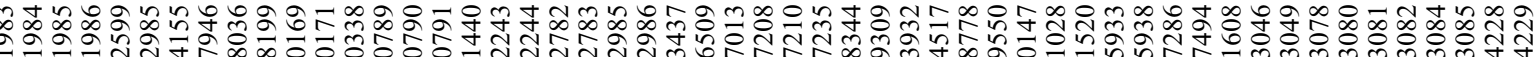

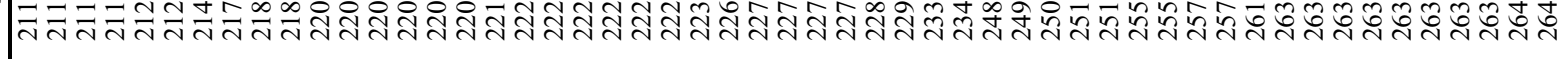

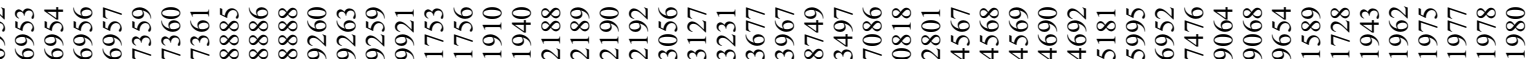

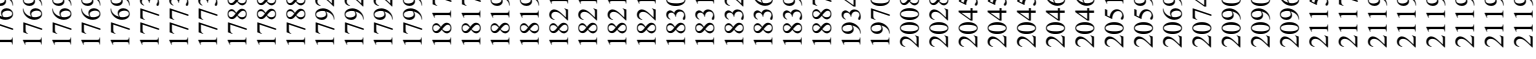

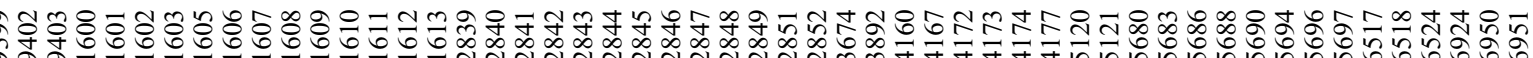

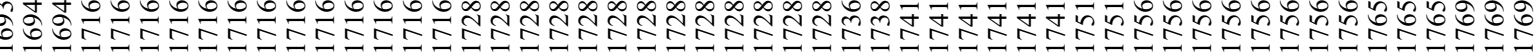

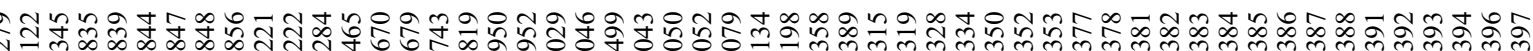

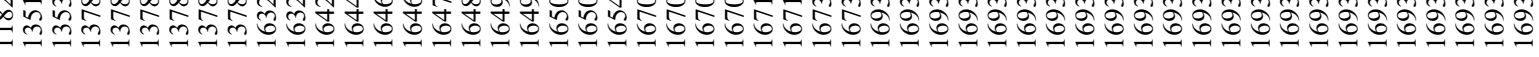

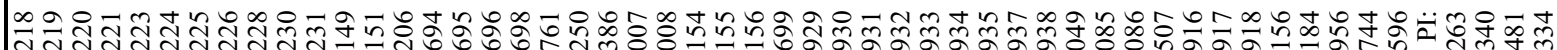
ปू. 